\title{
Practical work: Its effects on performance and motivation of non-physics major students
}

Naval, Dorothy $\$
Institute of Teaching and Learning, Philippine Normal University, Philippines (naval.dj@ pnu.edu.ph)

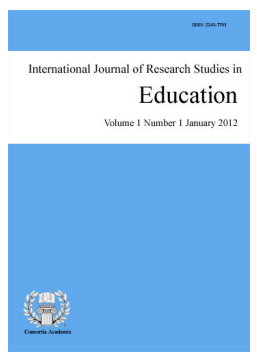

ISSN: 2243-7703

Received: 2 March 2020

Revised: 7 June 2020

Accepted: 22 June 2020

Available Online: 27 June 2020

\section{Abstract}

Many students find physics as a difficult subject which results in low achievement in all levels of education. To augment this issue, instructors look for ways on how to motivate and engage students in their course to explore physics concepts and science skills. The main purpose of the study was to determine the effects of practical work on students' performance and motivation in physics. The motivation of students to learn physics in college course was examined by responding to the Physics Motivation Questionnaire II (PMQ II) by Glynn (2011), 5-Likert scale with 25 items, and reliability of 0.92 assessed by Cronbach's alpha. Their performance in physics course was determined by pretest-posttest means using t-test. The result of the study showed that practical work promotes enjoyment, learning, and motivation to the non-physics major students. Males are most motivated intrinsically while females are highly career motivated. Moreover, students perform better in the posttest as revealed by their mean achievement scores. This approach was considered effective since there was an improvement in the students' performance in terms of knowledge acquisition.

Keywords: practical work; introductory physics; motivation 


\section{Practical work: Its effects on performance and motivation of non-physics major students}

\section{Introduction}

Many researchers have supported the views about the poor performance of the students in physics. Adeyemo (2010) concludes that one major reason for this poor performance might be the separation from the abstract course. The necessity of analytical techniques in almost all the topics in physics made it harder for the students to grasp. Another point is the rare real-life application of the artificial idealized systems in the said subject, where past syllabi are focused on. Making the impression that physics is a dying subject which is a serious consequence of the previous challenges. Furthermore, Finkelstein and Keller's (2004) study showed the different well-recognized challenges in teaching physics to different universities most especially for the non-physics majors. The traditional way of teaching, basically lecture and discussion do not engage students in the class. They are unmotivated when teachers are mostly using PowerPoint presentations and give overloading information. On the other hand, they are most likely to be engaged with laboratory works, field trips, and collaborative projects.

Motivation is an integral part of learning science. Many researchers in the field of science education have tried to explain why students contend to learn the subject. It includes the emotions they have as they strive, how intense the emotions are, and other factors that contribute to students' motivation. It is fundamental to examine the different factors of motivation for the teachers to be aware of how to sustain and increase the motivation of the students. Also, it is important in enhancing their instruction and teaching strategies. Several studies have examined the different factors that affect the students' performance in introductory physics. Students' learning is viewed as the most effective when they are engaged and motivated in different class works. In terms of classroom routines, the activities and the exercises should be designed in a way that promotes making links between the practical and the theoretical. Enough time and attention should be dedicated to discussing and reflecting on the connections between the natural world and the ideas of physics (Jokiranta, 2014).

According to Sadiq (2003); Lunetta, Hofstein, and Clough (2007) science is a subject that encourages students' to learning how the real world works, it is a body of knowledge that suggests being applied in real-life situations. Science teachers are being held responsible by the policymakers in regards to the lack of creativity and practical application of the students. Lunetta et al. (2007) suggested that the use of practical work offers simulation experiences that leave the students to learn using higher-order thinking skills and physically engaging in the learning process. An effective instructor creates a 'practical work' with specific objectives by using different pedagogical approaches that can be used in achieving learning outcomes. Palmer (2012) suggested contextualizing science practical work within applications of science in industry, medicine, or research. It also suggested activities that use practical work to solve authentic problems from science industries. Applying what students learned surprises the instructor when they are task to present their understanding of the lesson.

Hodson (1990) writes in his book A critical look at practical work in school science, the following objectives of practical work: (a) teach laboratory skills, (b) motivate students by stimulating interest and enjoyment, (c) enhance the learning of scientific knowledge, (d) give insight into the scientific method and develop expertise in using it, and (e) nurture scientific attitude. Science requires a hands-on and practical work whereas laboratories play a big role in it. The learning environment is fundamental for science education; the students are more interested when they can work freely. It will seem like they are just playing by simply observing and manipulating materials and objects. Learning then becomes easy while discovering science concepts and acquiring scientific skills (Hodson, 1990).

Science has been widely relevant to society and became a fast-changing body of knowledge. Students can formulate their scientific ideas to make sense of their simple observations. Effective teachers are those who 
Practical work: Its effects on performance and motivation of non-physics major students

empower the students to be decision-makers and maneuver the development of scientific methods individually. It is where they look for the answers in regards to the material or even to explain phenomena in the environment and society itself. Moreover, an effective teacher is capable of evaluating oneself and is reflective of the challenges of teaching to further develop the learner-centered approach.

The learner-centered approach has been tested for years already. It has been an effective approach to developing different 21 st-century skills such as creative and critical thinking skills. This approach is also known as interactive learning whereas hearing, seeing, and manipulating variables are the best way for the students to learn. Students' curiosity and imagination are stimulated through hands-on and minds-on activities which are based on a practical work approach. The role of the teacher in the learner-centered classroom is to act as the facilitator of learning. The teacher utilizes the interest and unique needs of every student, for them to experience meaningful learning. Through the use of a predetermined and developmental oriented objective, the learning of the students is assessed (SEI-DOST \& UP NISMED, 2011).

Furthermore, researchers of different subject domains have implemented practical work to promote students' motivation and engagement (TIMSS, 1995; Stanley, 2000), diagnose and remediate students' misconceptions (Daramola, 1987), motivate and interest students in science (Nashon, 1989), and endear the learners to be intake charge of their ability to investigate and question nature (Hirschfeld, 2012). A similar correlation was also found between understanding science subjects and practical work which lead to an improvement in achievement tests (Wasanga, 2009). Practical work allows the learners to take science learning seriously as demonstrated by Amunga, Musasia, and Musera (2011). This study investigated how practical work can help in learning introductory physics and getting more non-physics major students to get interested in the subject.

\subsection{Research questions}

Although many studies have been conducted on motivation and engagements, it is fundamental that more in-depth research be carried out to investigate the effects of practical work on the performance and motivation of non-physics major students. Hence, this study aims to answer the following research questions:

$>\quad$ What are the students' perceptions and motivations regarding practical work in physics?

$>$ How does practical work enhance student's performance in physics?

\subsection{Null hypothesis}

There is no significant difference between the mean scores of the pretest and posttest.

\section{Methodology}

\subsection{Research design}

This study used the one-group pretest-posttest design. This is a quasi-experimental research design in which the same dependent variable is measured in one group of participants before (pretest) and after (posttest) treatment is administered (Privitera \& Ahlgrim-Delzell, 2018) (see Figure 1, for more details).

\subsection{Respondents and sampling}

The participants of the study consist of 30 freshmen students under the course Physics 1 (Mechanics) in the academic year 2015-2016. To determine the effectiveness of practical work in physics, the researcher purposely selected fifteen (15) female students taking BS Psychology and another fifteen (15) male students taking BS Civil Engineering. A purposive sample also referred to as a judgmental or expert sample, is a type of nonprobability sample. The main objective of a purposive sample is to produce a sample that can be logically 
Naval, D.

assumed to be representative of the population. This is often accomplished by applying expert knowledge of the population to select in a nonrandom manner a sample of elements that represents a cross-section of the population (Lavrakas, 2008).

\begin{tabular}{|c|c|c|}
\hline \begin{tabular}{|c|} 
MEASUREMENT \\
Dependent Variable
\end{tabular} & $\begin{array}{c}\text { MEASUREMENT } \\
\text { Quasi-Independent Variable }\end{array}$ \\
\hline \begin{tabular}{c|c|c|} 
Measure \\
performance in \\
physics course using \\
California \\
Standardized Test
\end{tabular} & $\begin{array}{c}\text { Participants use } \\
\text { practical work in } \\
\text { physics course for } 8 \\
\text { weeks }\end{array}$ & $\begin{array}{c}\text { Measure } \\
\text { performance in } \\
\text { pependent Variable }\end{array}$ \\
\hline
\end{tabular}

Figure 1. Design of the study

\subsection{Research instruments}

The California Physics Standards Test (CPST) was used as a pretest to determine the readiness level of the respondents. The same test consisting of 44 multiple-choice questions was used as a posttest 8 weeks later. These questions represent only some ways in which 28 California content standards in mechanics may be assessed.

Physics Motivation Questionnaire II (PMQ II) is a 5-Likert scale survey. These 25 items included 16 from the original questionnaire-identically worded or with syntactic changes to improve comprehensibility-and 9 new items. As DeVellis (2003) recommends, the items are randomly ordered, strongly worded, unambiguous declarative statements in the form of short, simple sentences without jargon. Glynn et al (2011) categorized motivation into five components: intrinsic motivation, self-efficacy, self-determination, grade motivation, and career motivation. The Cronbach's alpha of all 25 items was 0.92 .

An expert-validated survey was used to assess the respondents' perceptions of the use of practical works in terms of learning, enjoyment, and motivation. Consequently, an unstructured interview with the participants is a follow up on the results of the intervention in the introductory physics course to better interpret the findings of the study.

\subsection{Data collection and ethical considerations}

The study was carried out over the 8 weeks in the semester of the 2015-2016 academic year. Participants were oriented on the use of practical work in the learning course, Physics 1 (Mechanics). Intensive practical activities have different components that guide students to the right concepts and skills in learning physics. They took the pretest before the intervention and the same test was given as a posttest to the participants at the end of the semester. Their performance was measured by investigating the differences in their pretest and posttest. They also responded to a survey questionnaire that assesses their motivation in learning physics. Lastly, respondents' perception of practical work in physics was measured using an expert-validated survey.

To participate in this study, respondents were asked to submit signed informed consent form and parental consent as applicable. Consent forms indicated the purpose of the study, the rights and roles of participants, and the statement of confidentiality to protect the participants' right to privacy. At any point during the conduct of the study, respondents may choose to discontinue their participation. 


\section{Results and discussions}

The following were the data obtained and the analyses of the study to answer the research questions:

Research Question 1: What are the students' perceptions and motivations regarding practical work in physics?

The participants were asked about their perceptions using practical work as a strategy in teaching to better understand physics. Their responses were categorized under three major themes (see table 1). The practical work used in the study gained positive responses from the respondents. Accordingly, $100 \%$ of the respondents enjoy practical work in physics; $93.33 \%$ were motivated while $96.67 \%$ said they learn physics concepts and skills.

\section{Table 1}

Perceptions of the respondents on practical work

\begin{tabular}{lcc}
\hline \multicolumn{1}{c}{ Category } & Frequency & Percent \\
\hline Enjoyment & 30 & 100.00 \\
Motivation & 28 & 93.33 \\
Learning & 29 & 96.67 \\
\hline
\end{tabular}

As gleaned from the table, two students enjoyed practical work but were not motivated and one of these two claimed that he did not learn using practical work. Both students are taking a civil engineering course. Lai (2011) suggested that motivation can be manipulated through certain instructional practices. Although students find class activities enjoyable using various strategies, one should ensure that these activities enhance motivation and learning. As it is the ultimate objective of every instruction: students stay in class because they are motivated to learn.

Some students have the following comments and suggestions (verbatim) in the use of practical work in learning introductory physics course:

I learned a lot not just about lessons; understanding its meaning and memorizing terms. But I also gained new knowledge on how to apply what I learned in real life and how our everyday lives include science. Science was never an easy subject but if you learn how to love it, you could understand its relevance.

Thank you for allowing me to creatively learn physics in a great and fun way...

More creative laboratory activities rather than laboratory activities...

I learned a lot in physics this semester...

Creative lab is more fun...

We need more time learning physics...

Science $=$ engineering...

The motivation of students to learn physics in college course was examined as they responded to the PMQ II. Respondents have a minimum response of 0 (never) and the maximum response of 4 (always) when asked to respond to the different statements from the perspective of "When I am in physics course...".

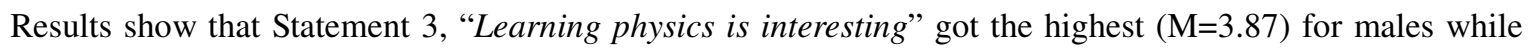
statement 20, "I think about the grade I will get in physics" got the highest (M=3.93) for females. A similar study showed that boys appear to view physics as valuable in itself and are pleased if there is internal coherence within the physics concepts learned whereas girls, tend to look for external coherence as outlined (Stadler, Duit, \& Benke, 2000). 


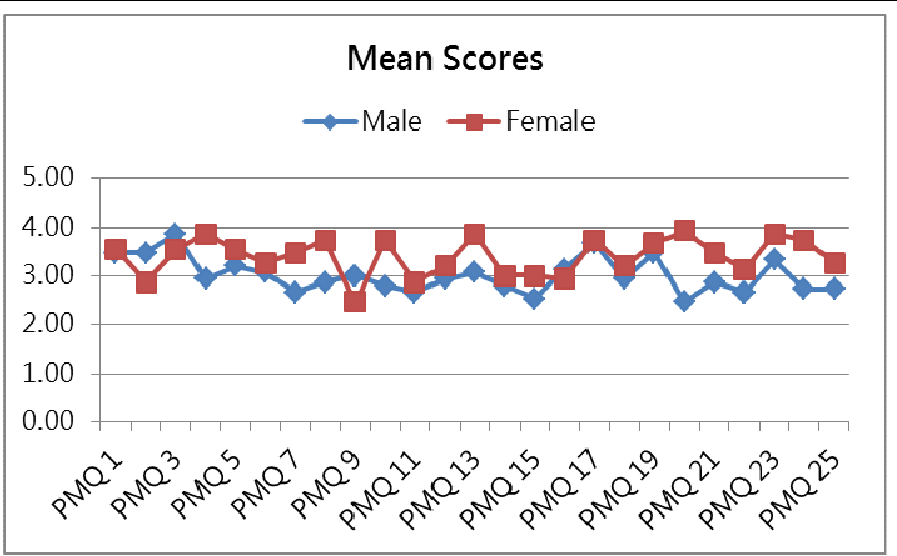

Figure 2. Mean scores of Physics Motivation Questionnaire II

Statement 17, "I am curious about discoveries in physics" was second highest for males (M=3.67) while three statements tied ( $\mathrm{M}=3.87)$ second-highest for females: statement 4, "Getting a good physics grade is important to me"; statement 13, "Understanding physics will benefit me in my career"; and statement 23, "My career will involve physics". While males are motivated intrinsically, it is found that females are extrinsically motivated - grade and career motivation.

To perform a task for its own sake is intrinsic. Males are found to be intrinsically motivated. They work on physics tasks because they find it interesting. On the other hand, females are found to be grade motivated. Motivation to perform a task as a means to an end is extrinsic. They are extrinsically motivated to work on physics tasks to attain a desirable outcome such as a good grade. Both types of motivation, intrinsic and extrinsic however, are important in contributing to students' success in their courses (Black \& Deci, 2000).

The overall response (see table 2) for both genders is greater than three (3) which means that students often think and feel that their course with the use of practical work promotes different types of motivation to perform better in their physics class.

\section{Table 2}

Summary of the mean of the different types of motivation

\begin{tabular}{llcc}
\hline Q\# & \multicolumn{1}{c}{ Statement } & Mean (Male) & Mean (Female) \\
\hline & Intrinsic Motivation & 3.47 & 3.53 \\
1 & The physics I learn is relevant to my life. & 3.87 & 3.53 \\
3 & Learning physics interesting. & 2.93 & 3.20 \\
12 & Learning physics makes my life more meaningful. & 3.67 & 3.73 \\
17 & I am curious about discoveries about physics. & 3.47 & 3.67 \\
19 & I enjoy learning physics. & 3.48 & 3.53 \\
\hline & $\quad$ Self-efficacy & & 2.47 \\
9 & I am confident that I will do well on physics test. & 3.00 & 3.00 \\
14 & I am confident that I will do well on physics labs and projects. & 2.80 & 3.00 \\
15 & I believe I can master physics knowledge and skills. & 2.53 & 3.20 \\
18 & I believe I can earn a grade of "A" in physics. & 2.93 & 3.47 \\
21 & I am sure I can understand physics. & 2.87 & 3.03 \\
& & 2.83 & 3.53 \\
\hline & & & 3.27 \\
5 & I put enough effort into learning physics. & 3.20 & 2.87 \\
6 & I use strategies to learn physics well. & 3.07 & 2.93 \\
11 & I spend a lot of time learning physics. & 2.67 & 3.13 \\
16 & I prepare well for physics tests and labs. & 3.13 & 3.15 \\
22 & I study hard to learn physics. & 2.67 & 2.95 \\
\end{tabular}


Practical work: Its effects on performance and motivation of non-physics major students

Table 2 ... continued

\begin{tabular}{llcc}
\hline Q\# & \multicolumn{1}{c}{ Statement } & Mean (Male) & Mean (Female) \\
\hline & & & \\
2 & I like to do better than other students on physics tests. & 3.47 & 2.87 \\
4 & Getting a good physics grade is important to me. & 2.93 & 3.87 \\
8 & It is important that I get an "A" in physics. & 2.87 & 3.73 \\
20 & I think about the grade that I will get in physics. & 2.47 & 3.93 \\
24 & Scoring high on physics tests and labs matters to me. & 2.73 & 3.73 \\
& & 2.89 & 3.63 \\
\hline \multicolumn{2}{c}{ Career Motivation } & 2.67 & 3.47 \\
7 & Learning physics will help me get a good job. & 2.80 & 3.73 \\
10 & Knowing physics will give me a career advantage. & 3.07 & 3.87 \\
13 & Understanding physics will benefit me in my career. & 3.33 & 3.87 \\
23 & My career will involve physics. & 2.73 & 3.27 \\
25 & I will use physics problem -solving skills in my career. & 2.92 & 3.64 \\
\hline
\end{tabular}

Male and female students are motivated differently. Males are mostly intrinsically motivated $(\mathrm{M}=3.48)$ while females tend to be career motivated $(M=3.64)$ and again females are grade motivated $(M=3.63)$ more than the males $(\mathrm{M}=2.89)$. Grade and career motivations are collectively called intrinsic motivation. In this study, students were highly motivated in their physics class, both intrinsically and extrinsically using practical work.

Both genders identified self-efficacy as their least motivation. Males ( $M=2.83)$ have lower self-efficacy than females $(M=3.03)$. Self-efficacy refers to students' beliefs about their capabilities in a specific area, which influences the choice of activities and achievement (Chemers, Hu, \& Garcia, 2001). Female respondents believed that they can achieve well in physics than males. The absence of the counterpart in class boosts their motivation to learn the introductory physics course. This is contrary to several studies. Hyde and Kling (2001) asserted that studies by Beyer and Bowden (1997), Eccles, Wigfield, and Schiefele (1998), and the U.S. Department of Education (2000) (as cited in Hyde \& Kling, 2001) indicate that women have less confidence in their abilities than do men.

Females have higher self-determination $(M=3.15)$ than males $(M=2.95)$. Self-determination refers to students having some choice in and control over their learning (Reeve, Nix, \& Hamm, 2003). When college science students have the opportunity to choose what their assignments will be, they are more likely to learn from the assignments (Glynn \& Koballa, 2006). Females believed they have control over their learning of physics and are more determined to accomplish and present their task in physics class. Consequently, they are more motivated to achieve higher grades than their counterpart.

Gender-wise practical activities have been found to benefit girls tremendously (Musasia, Abacha, \& Biyoyo 2012). Designing practical work in physics greatly motivated female participants of the study. They tend to engage and achieve more than their counterpart males. They believe that they can achieve well in physics courses and are determined to do so. The determination to meet physics objectives requirements of the practical tasks leads the student to be responsible for the learning situation and develop insight and course of action into the requirements of the task involved (Musasia, Ocholla, \& Sakwa 2016).

\section{Research Question 2: How does practical work enhance students' performance in physics?}

Mean scores of the pretest and posttest of the students indicated an increase using practical work in an introductory physics course. The figure below clearly revealed the mean gain of 19.33 for civil engineering students and 19.93 for students taking psychology. The result specified that males and females do not greatly differ in understanding physics concepts. This is contrary to the findings of Kost, Pollock, and Finkelstein (2009) and Musasia et al. (2016) where boys grasp physics concepts better than their counterpart girls. 
Naval, D.

Table 3

Mean and Standard Deviation pre-post-test raw score

\begin{tabular}{lllccc}
\hline & & Mean & $N$ & SD & SE Mean \\
\hline $\mathrm{CE}$ & Pretest & 17.40 & 15 & 11.89 & 3.07 \\
& Posttest & 36.73 & & 3.71 & .96 \\
Psych & Pretest & 16.80 & 15 & 6.00 & 1.55 \\
& Posttest & 36.73 & & 9.42 & 2.43 \\
\hline
\end{tabular}

To test if there is a significant difference in the mean achievement scores of the students, a paired samples t-test was computed.

\section{Table 4}

Significance level of CSTP pre-post test score

\begin{tabular}{cccccc}
\hline \multicolumn{1}{c}{ Statistics } & $M D$ & $S D$ & $t$ & $d f$ & $p$-value \\
\hline Pretest-Posttest (CE) & -19.33 & 11.22 & -6.676 & 14 & .000 \\
Pretest-Posttest (Psych) & -19.93 & 8.59 & -8.988 & 14 & .000 \\
\hline
\end{tabular}

Table 5

Summary of computations

\begin{tabular}{lcccccc}
\hline Subject & Category & Mean & Computed t-test & Computed $p$-value & Decision & Remarks \\
\hline CE & Pretest-Posttest & -19.33 & -6.68 & .0000 & Reject Ho & Significant \\
Psych & Pretest-Posttest & -19.93 & -8.99 & .0000 & Reject Ho & Significant \\
\hline
\end{tabular}

Based on the table, the computed p-value is less than the .05 level of significance. The decision is to reject the null hypothesis: There is a significant difference between the mean scores of the pretest and posttest. These results suggest that the use of practical work does affect students' performance. Specifically, the results propose that when students use this approach, their performance in physics enhances. Similar to the study of Musasia et al. (2016) which showed that the instructional method (practical work) used in teaching experimental groups was more effective than that used in the control group. It can be perceived that students perform better using practical work. This was considered effective in physics instruction since there was an improvement in the context or knowledge acquisition.

\section{Conclusions and recommendations}

Practical work in physics instruction promotes enjoyment, learning, and motivation to the freshmen non-physics major students. Teachers become more effective educators and students become more active by engaging them in learning tasks. Students often think and feel that their course with the use of practical work promotes different types of motivation to perform better in their physics class. Males are intrinsically motivated. They are more interested and find satisfaction in learning physics. Females on the other hand, are extrinsically motivated. They learn physics as a means to a tangible end, such as a career or a grade.

The study showed that practical work has a positive effect on students' achievement in physics. Students perform better using practical work. Achievement in physics course was manifested as practical work enhanced student's performance. This was confirmed by rejecting the null hypothesis: There is a significant difference between the mean scores of pretest and posttest.

This study recommends the use of practical work in other areas based on the learning competencies which can be used to motivate students in different science courses. The use of different assessment tools to measure the effectiveness of practical work may be explored. Instead of a paper-pencil test, a researcher may employ the use of rubrics for performance tasks. Finally, replicate the study using a large population, randomized sampling 
techniques, and a longer period between pretests and posttests.

\subsection{Limitations of the study}

The California Standards Tests (CSTs) measure the achievement of California content standards in English-language arts, mathematics, science, and history-social science for grades 2-11. Grade 11 is of the same level as freshmen college students during the conduct of the study since the Philippines have not yet adopted the K12 curriculum. Participants of the study are included in the last batch who did not take senior high school under the new curriculum.

Acknowledgments: The author thank Maria Sofia M. Dela Peña for assistance with some invaluable information, and exacting attention to details, and Prof. Joseph Erfe for giving meaningful insights and comments that greatly improve the manuscript. I also thank the BS Psychology and BS Civil Engineering freshmen of A.Y. 2015-2016 for giving their time and effort in participating in this research.

\section{References}

Adeyemo, S. A. (2010). Teaching/learning physics in Nigerian secondary school: The curriculum transformation, issues, problems, and prospects. International Journal of Educational Research and Technology, 1(1), 99-111.

Amunga, J. K., Musasia, M. A., \& Musera, G. (2011). Disparities in the physics achievement and enrolment in secondary schools in western province: Implications for strategy and renewal. Problems of Education in the 21 st Century, 31, 18-32.

Black, A. E., \& Deci, E. L. (2000). The effects of instructors' autonomy support and students' autonomous motivation on learning organic chemistry: A self-determination theory perspective. Science Education, 84, 740-756. https://doi.org/10.1002/1098-237X(200011)84:6<740::AID-SCE4>3.0.CO;2-3

Chemers, M. M., Hu, L., \& Garcia, B. F. (2001). Academic self-efficacy and first-year college student performance and adjustment. Journal of Educational Psychology, 93, 55-64. https://doi.org/10.1037/0022-0663.93.1.55

Daramola, S. O. (1987). Restructuring science education programmes in Nigerian higher institutions. Journal of Curriculum and Instruction, $2(1 \& 2), 235-240$.

DeVellis, R. F. (2003). Scale development: Theory and applications (2nd ed.). Thousand Oaks, CA: Sage.

Finkelstein, N., \& Keller, C. (2004). Laboratory revisions physics 2010 and physics 2020. Boulder, CO: Department of Physics, University of Colorado.

Glynn, S. M. (2011). Science Motivation Questionnaire II (SMQ II): Components. Athens, GA: University of Georgia. https://doi.org/10.1037/t42503-000

Glynn, S. M., \& Koballa, T. R. (2006). Motivation to learn college science. In J. J. Mintzes \& W. H. Leonard (Eds.), Handbook of college science teaching (pp. 25-32). Arlington, VA: National Science Teachers Association Press.

Glynn, S. M., Brickman, P., Armstrong, N., \& Taasoobshirazi, G. (2011). Science motivation questionnaire II: Validation with science majors and non-science majors. Journal of Research in Science Teaching, 48(10), 1159-1176. https://doi.org/10.1002/tea.20442

Hirschfeld, D. (2012). Interest in science careers wanes in Latin America. Retrieved from https://www.scidev.net/global/capacity-building/news/interest-in-science-careers-wanes-in-latin-americ $\underline{\text { a.html }}$

Hodson, D. (1990). A critical look at practical work in school science. School Science Review, 71, 33-40.

Hyde, J. S., \& Kling, K. C. (2001). Women, motivation, and achievement. Psychology of Women Quarterly, 25 , 364-378. https://doi.org/10.1111/1471-6402.00035

Jokiranta, K. (2014). The effectiveness of practical work in science education [Bachelor Thesis]. Department of 
Naval, D.

Physics, University of Jyväskylä.

Kost, L., Pollock, S., \& Finkelstein, N. (2009). Characterizing the gender gap in introductory physics. Physical Review Physics Education Research, 5. https://doi.org/10.1103/PhysRevSTPER.5.010101

Lai, E.R. (2011) Motivation: A literature review. Pearson Research Report. Retrieved from https://images.pearsonassessments.com/images/tmrs/Motivation_Review_final.pdf

Lavrakas, P. J. (2008). Encyclopedia of survey research methods. Thousand Oaks, CA: Sage Publications. https://doi.org/10.4135/9781412963947

Lunetta, V. N., Hofstein, A., \& Clough, M. P. (2007). Teaching and learning in the school science laboratory. An analysis of research, theory, and practice. In S. K. Abell \& N. G. Lederman (Eds.), Handbook of research on science education (pp. 393-431). Mahwah, NJ: Lawrence Erlbaum Associates.

Musasia, A. M., Abacha, O. A., \& Biyoyo, M. E. (2012). Effect of practical work in physics on girls' performance, attitude change, and skills acquisition in the form two-form three secondary schools' transition in Kenya. International Journal of Humanities and Social Science, 2(23), 151-166.

Musasia, A. M., Ocholla, A. A., \& Sakwa, T. W. (2016). Physics practical work and its influence on students' academic achievement. Journal of Education and Practice, 7(28), 129-134.

Nashon, S. M. (1989). Practical work in science: A critical look at practical work in Kenyan secondary schools [Masteral Thesis]. School of Education, The University of Leeds.

Palmer, E. (2012). Practical work for learning. Brief for research review: Theme 3. Personal correspondence. London: Nuffield Foundation.

Privitera, G. J., \& Ahlgrim-Delzell, L. (2018). Quasi-experimental and single-case experimental designs. In Research methods for education (pp.333-370). Los Angeles, CA: Sage.

Reeve, J., Nix, G., \& Hamm, D. (2003). Testing models of the experience of self-determination in intrinsic motivation and the conundrum of choice. Journal of Educational Psychology, 95, 375-392. https://doi.org/10.1037/0022-0663.95.2.375

Sadiq, A. (2003). Evaluation of scientific enterprise in Pakistan. In Inayatullah (Ed.), Towards understanding the state of science in Pakistan (pp. 89-132). Karachi, Pakistan: Council of Social Science.

SEI-DOST \& UP NISMED. (2011). Framework for Philippine science teacher education. Manila: SEI-DOST \& UP NISMED.

Stadler, H., Duit, R., \& Benke, G. (2000). Do boys and girls understand physics differently? Physics Education, 35(6), 417-422. https://doi.org/10.1088/0031-9120/35/6/307

Stanley, H. E. (2000). Exotic statistical physics: Applications to biology, medicine, and economics. Physics A, 285, 1-17. https://doi.org/10.1016/S0378-4371(00)00341-1

Trends in International Mathematics and Science Study (TIMSS). (1995). International reports in mathematics and science (1995, 1999). Retrieved from http://timss.bc.edu/timss1999.html

Wasanga, P. M. (2009). The role of examination results as a feedback tool: The Kenyan experience. In First READ global conference: Developing a vision for assessment systems (pp. 13-15). Moscow, Russia. 